\title{
Dataset Paper Molecular Data for the Sea Turtle Population in Brazil
}

\author{
Sibelle Torres Vilaça and Fabricio Rodrigues dos Santos \\ Laboratório de Biodiversidade e Evolução Molecular (LBEM), Instituto de Ciências Biológicas, \\ Universidade Federal de Minas Gerais (UFMG), Avenida Antônio Carlos 6627, 31270-010 Belo Horizonte, MG, Brazil \\ Correspondence should be addressed to Fabricio Rodrigues dos Santos; fsantos@icb.ufmg.br
}

Received 3 June 2013; Accepted 20 June 2013

Academic Editors: G. Hill and S. Kleinsteuber

Copyright (C) 2013 S. T. Vilaça and F. R. dos Santos. This is an open access article distributed under the Creative Commons Attribution License, which permits unrestricted use, distribution, and reproduction in any medium, provided the original work is properly cited.

\begin{abstract}
We report here a dataset comprising nine nuclear markers for the Brazilian population of Cheloniidae turtles: hawksbills (Eretmochelys imbricata), loggerheads (Caretta caretta), olive ridleys (Lepidochelys olivacea), and green turtles (Chelonia mydas). Because hybridization is a common phenomenon between the four Cheloniidae species nesting on the Brazilian coast, we also report molecular markers for the hybrids E. imbricata $\times$ C. caretta, C. caretta $\times$ L. olivacea, and E. imbricata $\times$ L. olivacea and for one hybrid E. imbricata $\times$ C. mydas and one between three species C. mydas $\times$ E. imbricata $\times$ C. caretta. The data was used in previous studies concerning (1) the description of frequent hybrids C. caretta $\times$ E. imbricata in Brazil, (2) the report of introgression in some of these hybrids, and (3) population genetics. As a next step for the study of these hybrids and their evolution, genome-wide studies will be performed in the Brazilian population of E. imbricata, C. caretta, and their hybrids.
\end{abstract}

\section{Introduction}

From the seven known sea turtle species, five species nest on the Brazilian coast: leatherback (Dermochelys coriacea), green (Chelonia mydas), olive ridley (Lepidochelys olivacea), loggerhead (Caretta caretta), and hawksbill (Eretmochelys imbricata). The Brazilian sea turtle population differs from other worldwide populations because of its high hybrid frequency. Almost $43 \%$ of nesting E. imbricata individuals were reported as hybrids in a short stretch of the Brazilian coast (Bahia state), while other sites where E. imbricata nests did not show presence of hybrids $[1,2]$.

The sea turtles that nest in the Brazilian coast have been shown to form a separate genetic pool from other populations [3-5]. Studies with species nesting in Brazil show that their populations are differentiated from other worldwide populations. Recent telemetry studies corroborate the results from genetic data: C. caretta, E. imbricata, C. mydas, and $L$. olivacea individuals that nest in Brazilian beaches tend to stay in feeding aggregations within the Brazilian continental shelf [6-9]. On the other hand, Brazilian feeding aggregations are characterized by a mixture of turtles coming from different regions worldwide. Mixed-stock results based on mitochondrial DNA showed that E. imbricata feeding areas receive migrants from Africa, Caribbean, and Pacific Ocean [10]; C. caretta foraging aggregations are characterized by a mixture of Brazilian, Australian, Mediterranean, and northwestern Atlantic turtles [3]; and C. mydas feeding grounds are characterized by the contribution of other Atlantic sites [4]. Regarding L. olivacea, no genetic study dealing with feeding aggregations in Brazil was published so far.

Sea turtle populations nesting in Brazil exhibit a significant genetic differentiation from other turtle populations and are also characterized by their unique high incidence of hybrids. Even though hybrids have been reported in other populations, they were observed only sporadically (Table 1). Moreover, the Brazilian population is singular since more than one type of hybrid is present along the coast. With the exception of $D$. coriacea, the other four species are capable of hybridizing $[1,2]$. Hybrids involving four different species are currently described, and introgression (i.e., backcrossing with one parental species) is not observed in all of them. Generally, most hybrids are F1, with only a small portion being reported as $>$ F1.

The interspecific hybridization is recognized in several studies, and so far five hybrid types were described in Brazilian waters based on morphology and nuclear markers: the frequent hybrid E. imbricata $\times C$. caretta; the less frequent 
TABLE 1: Brief description of studies that reported sea turtle hybrids. Hybrid cross refers to the species that produced the hybrid, Site indicates where the hybrids were found, Analysis indicates how the hybrids were identified (mtDNA indicates the mitochondrial DNA was sequenced and scnDNA indicates that single-copy nuclear DNA was typed using RFLP), $N$ refers to the number of hybrids analysed in each study. A question mark indicates it was not possible to obtain the number of hybrids analysed.

\begin{tabular}{|c|c|c|c|c|}
\hline Hybrid cross & Site & Analysis & $N$ & Reference \\
\hline \multirow{5}{*}{$\begin{array}{l}\text { Chelonia mydas } \times \\
\text { Eretmochelys imbricata }\end{array}$} & Western Atlantic (Suriname) & Allozymes & $23^{1}$ & {$[20]$} \\
\hline & Western Atlantic (Suriname) & mtDNA, scnDNA & 1 & {$[21]$} \\
\hline & Eastern Pacific (Mexico) & mtDNA, scnDNA, morphology & 1 & {$[22]$} \\
\hline & Western Atlantic (Brazil) & $\begin{array}{l}\text { mtDNA, morphology, scnDNA, } \\
\text { microsatellites, nuclear sequences }\end{array}$ & 1 & {$[2]$} \\
\hline & Western Pacific (Japan) & Morphology & $?$ & {$[23]$} \\
\hline \multirow{4}{*}{$\begin{array}{l}\text { Chelonia mydas } \times \\
\text { Caretta caretta }\end{array}$} & Western Pacific (Australia) & Morphology & $?$ & $\begin{array}{l}\text { C. Limpus, personal } \\
\text { communication [22] }\end{array}$ \\
\hline & Western Pacific (Japan) & Morphology & $?$ & {$[24]$} \\
\hline & Western Atlantic (Brazil) & mtDNA, scnDNA & 4 & {$[21]$} \\
\hline & Western Atlantic (Canada) & mtDNA, morphology & 1 & {$[25]$} \\
\hline \multirow{8}{*}{$\begin{array}{l}\text { Caretta caretta } \times \\
\text { Eretmochelys imbricata }\end{array}$} & Western Pacific (Japan) & Morphology & $?$ & {$[26]$} \\
\hline & Western Pacific (China) & Morphology & 1 & [27] \\
\hline & Western Atlantic (Brazil) & Allozymes & 1 & [28] \\
\hline & Western Atlantic (USA) & mtDNA, scnDNA & 2 & {$[21]$} \\
\hline & Western Atlantic (Brazil) & $\begin{array}{l}\text { mtDNA, morphology, scnDNA, } \\
\text { microsatellites, nuclear sequences }\end{array}$ & 50 & {$[1,2]$} \\
\hline & Western Atlantic (Brazil) & mtDNA & 10 & {$[29]$} \\
\hline & Western Atlantic (USA) & Morphology & 1 & {$[30]$} \\
\hline & Western Pacific (Japan) & Isozymes & $?$ & {$[31]$} \\
\hline \multirow{2}{*}{$\begin{array}{l}\text { Lepidochelys kempii } \times \\
\text { Caretta caretta }\end{array}$} & Western Atlantic (USA) & mtDNA, scnDNA & 1 & {$[21]$} \\
\hline & Western Atlantic (USA) & mtDNA, microsatellites & 3 & {$[32]$} \\
\hline $\begin{array}{l}\text { Lepidochelys olivacea } \times \\
\text { Chelonia mydas }\end{array}$ & Western Atlantic (Brazil) & Morphology & $?$ & $\begin{array}{l}\text { M. Marcovaldi, personal } \\
\text { communication }[22]\end{array}$ \\
\hline $\begin{array}{l}\text { Lepidochelys olivacea } \times \\
\text { Eretmochelys imbricata }\end{array}$ & Western Atlantic (Brazil) & $\begin{array}{l}\text { mtDNA, morphology, scnDNA, } \\
\text { microsatellites, nuclear sequences }\end{array}$ & 2 & {$[1,2]$} \\
\hline $\begin{array}{l}\text { Lepidochelys olivacea } \times \\
\text { Caretta caretta }\end{array}$ & Western Atlantic (Brazil) & $\begin{array}{l}\text { mtDNA, morphology, scnDNA, } \\
\text { microsatellites, nuclear sequences }\end{array}$ & 14 & {$[2,3]$} \\
\hline
\end{tabular}

${ }^{1}$ All turtles belonged to a single hatch.

hybrids C. caretta $\times$ L. olivacea, E. imbricata $\times$ L. olivacea, and C. mydas $\times$ L. olivacea; and even one hybrid between three species $C$. $m y d a s \times E$. imbricata $\times C$. caretta. Even though most hybrids found are F1, this hybrid between three species is supposed to be an E. imbricata $\times C$. caretta F1 that crossed with a C. mydas [2]. In a large survey, Vilaça et al. [2] found that feeding aggregations of E. imbricata and C. caretta within the Brazilian continental shelf do not exhibit the presence of hybrids, with only two exceptions of one C. caretta $\times L$. olivacea hybrid being found in São Paulo state and one $C$. caretta $\times$ E. imbricata being found in the oceanic feeding area of Atol das Rocas.

Here we describe the data from Vilaça et al. [2]. The dataset presented in this paper refers to the first populational study in sea turtles using nuclear sequences. It focuses on the Brazilian population of E. imbricata, C. caretta, L. olivacea, C. mydas, and their hybrids. A total of five nuclear markers were sequenced, and four microsatellites were genotyped in samples that already had a mitochondrial locus (D-loop) typed in previous studies $[1,3]$. Detailed information of the allele frequencies in several nuclear loci is obtained from the data.

\section{Methodology}

The DNA of 387 sea turtle samples from the Brazilian coast was sequenced (Figure 1). We sequenced the DNA of four Cheloniidae species that nest in Brazil: 168 samples from C. caretta, 121 from E. imbricata, 22 from L. olivacea, and nine C. mydas. We chose to analyse these four species for three main reasons: (i) to construct a detailed database of the allele frequencies in the Brazilian populations, (ii) to establish the typical alleles of each species, and (iii) to use the alleles present in each species to investigate the hybrids present in the Brazilian coast. For these presumably "pure" samples, all individuals had both morphology and mitochondrial DNA (mtDNA) of the respective species. This is a strong indication that these samples belong to "nonhybrid" individuals, since previous studies showed that hybrids had intermediate morphology (or a mix of different morphological characters) 


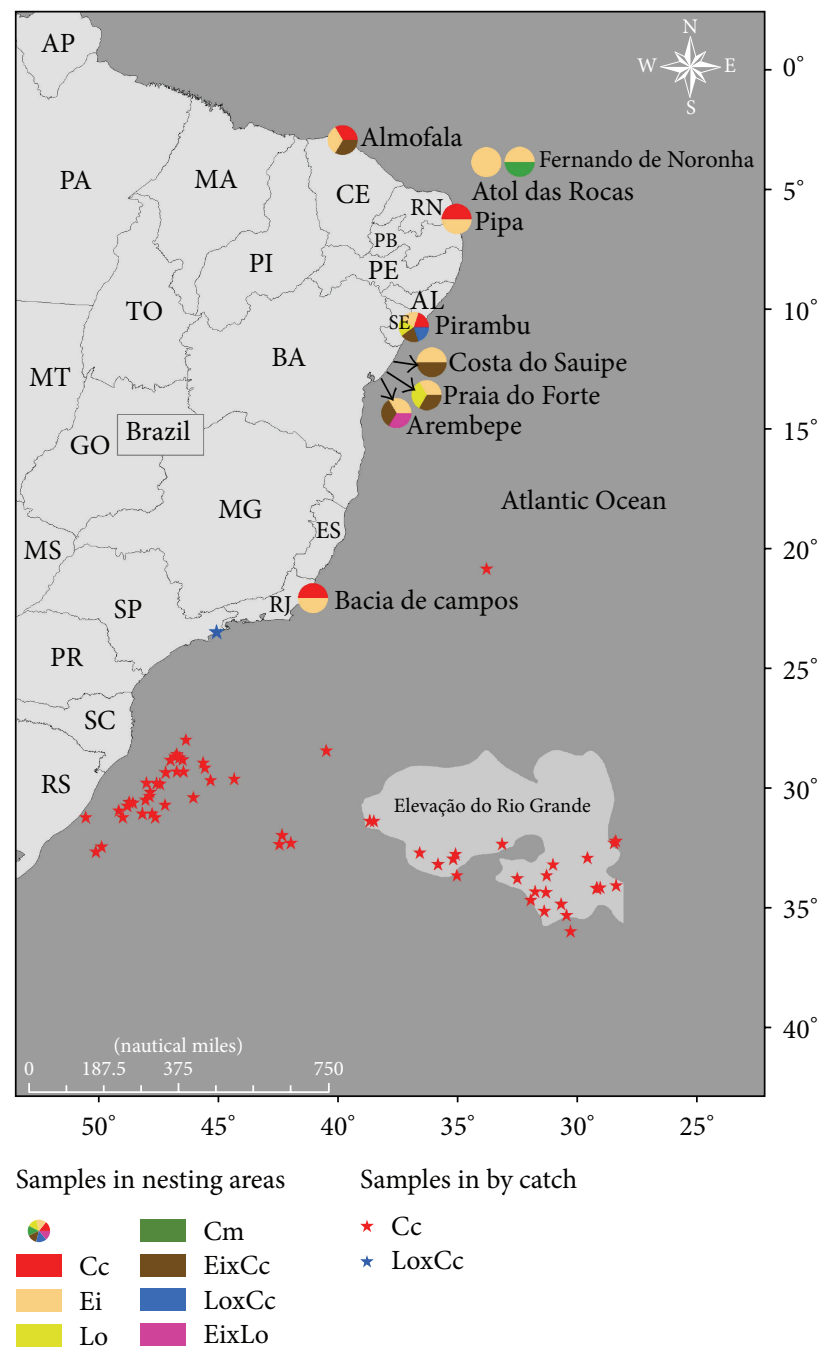

FIGURE 1: Map displaying the sampling locations along the Brazilian coast. Circles do not refer to sample proportions but represent the species or hybrid class samples found in each area. Cc: Caretta caretta; Ei: Eretmochelys imbricata; Lo: Lepidochelys olivacea; Cm: Chelonia mydas.

and mtDNA from different species. These loci were used to describe the genetic diversity within species and to establish the typical (private) alleles for each species. Caution was taken for areas where hybrids had been previously reported; except for the nesting sites in Bahia and Sergipe coastlines, no hybrid was previously registered among nesting or bycatch individuals from the sampling sites. This is particularly important since samples from presumably "pure" individuals from these areas (Bahia and Sergipe) were taken under extra care in establishing private alleles, since they could be hybrid samples.

Of the 387 samples, 66 individuals previously identified as hybrids (morphology of one species and mtDNA from a different one) were analysed with nuclear markers. Those included 50 hybrids of $C$. caretta $\times$ E. imbricata, two hybrids of $E$. imbricata $\times L$. olivacea, and 14 hybrids of $L$. olivacea $\times C$. caretta analysed.

Some samples of C. caretta $\times E$. imbricata hybrids were especially interesting, since they allowed a more detailed view of the hybridization process. Samples of four siblings derived from a single clutch (R0264, R0265, R0267, and R0268) were collected in Praia do Forte, Bahia, and possessed C. caretta mitochondria, but the morphology indicated a possible hybridization between E. imbricata and C. mydas. Another sample used included one hatchling (R0025) of a C. caretta $\times$ E. imbricata hybrid female (R0024). Both samples had mtDNA from C. caretta. Besides the four siblings from a single clutch and the hatchling R0025, all other hybrid samples were adult nesting females.

We have also included one bycatch sample (R0384) that was previously classified by morphology as C. caretta but identified by mtDNA as a $L$. olivacea $\times C$. caretta hybrid from the São Paulo State.

A total of five nuclear markers were sequenced to evaluate the presence of interspecific variation. We used four exons (brain-derived neurotrophic factor $(B D N F)$, oocyte maturation factor (CMOS), and two recombination activatinggenes (RAG1 and RAG2)) and one intron (RNA fingerprint protein 35 gene (R35)) to identify species-specific alleles and their frequency in hybrids. 
TABLE 2: Primer sequences used to amplify the nuclear sequences with annealing temperatures and enhancers used in the PCR reaction.

\begin{tabular}{lccc}
\hline Primer & Sequence $\left(5^{\prime}-3^{\prime}\right)$ & Annealing temperature $\left({ }^{\circ} \mathrm{C}\right)$ & Enhancers \\
\hline RAG1F & AGTCCATCTCTTGCCAGGTC & 61.5 & BSA 1X \\
RAG1R & CAGCAGGAACAAAGTTAGGC & & Gelatin 0.001\% \\
RAG2F & CTGCTATCTTCCCCCTCTCC & 68 & Gelatin 0.001\% \\
RAG2R & GTTGTCACACTGGTAGCCCC & 53.5 & Gelatin $0.001 \%$ \\
R35F & CAAGTGAGTCCTTTGCTGG & & \\
R35R & CAGCCATCTGTATCTGAAAGG & 68 & Gelatin $0.001 \%$ \\
CMOSF & ATTGTGCCTACTACAGCCCC & & \\
CMOSR & ATATGTGCCCCCCTGCTG & 6.5 & \\
BDNFF & TCTGGAGAGCCTAAGTGGG & & \\
BDNFR & TAAACCGCCAGCCAACTC & & \\
\hline
\end{tabular}

PCR reaction mixes of $15 \mu \mathrm{L}$ included $50 \mathrm{ng}$ of genomic DNA, $1 \mathrm{U}$ of Taq polymerase (Phoneutria), $200 \mu \mathrm{M}$ of dNTPs, $1 \mathrm{X}$ Tris-KCl buffer with $1.5 \mathrm{mM} \mathrm{MgCl}_{2}$ (Phoneutria), and $1 \mu \mathrm{M}$ of each primer. PCR enhancers and primer sequences used for each amplified locus are shown in Table 2. The amplification program consisted of $3 \mathrm{~min}$ at $94^{\circ} \mathrm{C}$, followed by 35 cycles of $40 \mathrm{~s}$ at $94^{\circ} \mathrm{C}, 45 \mathrm{~s}$ at $45-50^{\circ} \mathrm{C}, 50 \mathrm{~s}$ at the annealing temperature of each primer, and a final extension step of $10 \mathrm{~min}$ at $72^{\circ} \mathrm{C}$. After amplification, PCR products were checked by running in a $0.8 \%$ agarose gels and stained with ethidium bromide. These products were cleaned by precipitation using $20 \%$ polyethylene glycol and $2.5 \mathrm{M} \mathrm{NaCl}$ before loading to the sequencing reactions, which were performed using either of the amplification primers. The sequencing reaction was performed with ET DYE Terminator Kit (GE Healthcare) according to the manufacturer's instructions. Then, sequencing products were precipitated and run in the automatic sequencer MegaBACE 1000 (GE Healthcare).

High-quality consensus sequences were obtained using the programs Phred [11], Phrap [12], and Consed 16.0 [13]. The consensus sequences of the autosomal loci were aligned by the Clustal X algorithm implemented in MEGA5 [14] together with the two E. imbricata and C. caretta reference sequences published by Naro-Maciel et al. [15]. Polymorphic sites were identified by visual inspection in Consed or using Polyphred $6.11[16,17]$.

We genotyped four autosomal microsatellites developed for L. olivacea and C. caretta. These loci included OR1 and OR3 [18], and Cc1G02 and Cc1G03 [19]. All genotypes were evaluated to determine species-specific alleles.

Polymerase chain reaction (PCR) mixes of $9 \mu \mathrm{L}$ included $1 \mu \mathrm{L}$ of genomic DNA ( 40 ng), $1 \mathrm{U}$ of Taq Platinum polymerase (Invitrogen), $200 \mu \mathrm{M}$ of deoxynucleoside triphosphates, $1 \mathrm{X}$ Tris-KCl buffer (Invitrogen), $1.5 \mathrm{mM} \mathrm{MgCl}_{2}$ (Invitrogen), $1 \mathrm{mM}$ of the forward primer labeled with an $\mathrm{m} 13$ tail, $10 \mathrm{mM}$ of the reverse primer, and $10 \mathrm{mM}$ of the $\mathrm{m} 13$ primer with fluorescence FAM or HEX. The amplification program consisted of $3 \mathrm{~min}$ at $94^{\circ} \mathrm{C}$, followed by 30 cycles of $30 \mathrm{~s}$ at $94^{\circ} \mathrm{C}, 30 \mathrm{~s}$ at annealing temperatures depending on the locus $\left(55^{\circ} \mathrm{C}\right.$ for OR1, OR2, and OR3 and $60^{\circ} \mathrm{C}$ for $\mathrm{CC} 1 \mathrm{G} 02$ and $\mathrm{Cc1G03),} 30 \mathrm{~s}$ at $72^{\circ} \mathrm{C}$, and a final extension step of $30 \mathrm{~min}$ at $72^{\circ} \mathrm{C}$. The amplicons were diluted fivefold with Milli-Q water. Genotyping reaction mixes of $10 \mu \mathrm{L}$ included $2 \mu \mathrm{L}$ of diluted amplicon, $0.25 \mu \mathrm{L}$ of ET 550-R (GE Healthcare), and $7.75 \mu \mathrm{L}$ of Tween $200.1 \%$. The running conditions followed the manufacturer's recommendations (GE Healthcare) for genotyping in an automated MegaBACE 1000 DNA analysis system. The peaks were analyzed in the Fragment Profiler Program (GE Healthcare) for allele scoring.

Dataset was constructed as follows. From the 387 samples typed for the nine nuclear markers, we selected the samples with a maximum of two missing markers. We did this selection, so the analysis to infer the genetic diversity of the turtle populations, and hybrid inference were not affected by the missing data. The final dataset was composed of 223 samples of the four species, and their hybrids, with at least seven typed loci. The only exception was a hybrid from $E$. imbricata $\times$ L. olivacea and one C. mydas sample, both typed for six loci.

\section{Dataset Description}

The dataset associated with this Dataset Paper consists of 8 items which are described as follows.

Dataset Item 1 (Table). The detailed genetic data obtained. The column popID is an identification number of each population, given by a combination of morphology and mtDNA and, therefore, previous to the analysis with nuclear loci. Number 1 refers to E. imbricata $\times C$. caretta hybrids, number 2 to E. imbricata $\times$ L. olivacea hybrids, number 3 to E. imbricata "pure" samples, number 4 to C. caretta "pure" samples, number 5 to L. olivacea $\times C$. caretta hybrids, number 6 to L. olivacea "pure" samples, and number 7 to C. mydas "pure" samples. The column Sample Code is an identification code for each sample. The codes starting with R0XX are deposit codes in the DNA Bank DB-LBEM at the Federal University of Minas Gerais. The column Hybrid/Species is an identification code that summarizes the results obtained with the nuclear data and classifies the sample in a category of hybrid or pure individual. The code EixCc refers to an $E$. imbricata $\times C$. caretta hybrid; Ei refers to an E. imbricata pure individual; $C c$ refers to a $C$. caretta pure individual, EixCcxCm refers to an E. imbricata $\times$ C. caretta $\times$ C. mydas hybrid, EixCm refers to an E. imbricata $\times C$. mydas hybrid, 
EixLo refers to an E. imbricata $\times$ L. olivacea hybrid, LoxCc refers to an L. olivacea $\times$ C. caretta hybrid, Lo refers to an $L$. olivacea pure individual, and $\mathrm{Cm}$ refers to a C. mydas pure individual. The column Morphology gives the species classification based on morphology. Codes are the same as in the column Hybrid/Species. The column mtDNA refers to the mitochondrial results from the locus D-loop. Codes are the same as in the column Hybrid/Species. The columns 6 to 23 identify the alleles found for each of the loci typed. Columns OR1 Allele 1 and OR1 Allele 2 identify the two alleles for the microsatellite loci OR1. Each column is one allele present in this locus. Columns OR3 Allele 1 and OR3 Allele 2 are the alleles for the microsatellite loci OR3. Columns CC1G02 Allele 1 and CC1G02 Allele 2 are the alleles for the microsatellite loci CC1G02. Columns CC1G03 Allele 1 and CC1G03 Allele 2 are the alleles for the microsatellite loci CC1G03. Columns RAG1 Allele 1 and RAG1 Allele 2 are the alleles for the locus RAG1. Columns CMOS Allele 1 and CMOS Allele 2 are the alleles for the locus CMOS. Columns RAG2 Allele 1 and RAG2 Allele 2 are the alleles for the locus RAG2. Columns R35 Allele 1 and R35 Allele 2 are the alleles for the locus R35. Columns BDNF Allele 1 and BDNF Allele 2 are the alleles for the locus BDNF. No data is shown by a question mark. In the table, the asterisk $(*)$ indicates samples and/or loci with introgression with E. imbricata, the double asterisk $(* *)$ indicates samples and/or loci with introgression with $C$. caretta, and the triple asterisk $(* * *)$ indicates samples and/or loci with introgression with L. olivacea.

$\begin{array}{ll}\text { Column 1: } & \text { popID } \\ \text { Column 2: } & \text { Sample Code } \\ \text { Column 3: } & \text { Hybrid/Species } \\ \text { Column 4: } & \text { Morphology } \\ \text { Column 5: } & \text { mtDNA } \\ \text { Column 6: } & \text { OR1 Allele 1 } \\ \text { Column 7: } & \text { OR1 Allele } 2 \\ \text { Column 8: } & \text { OR3 Allele } 1 \\ \text { Column 9: } & \text { OR3 Allele } 2 \\ \text { Column 10: } & \text { CC1G02 Allele 1 } \\ \text { Column 11: } & \text { CC1G02 Allele } 2 \\ \text { Column 12: } & \text { CC1G03 Allele } 1 \\ \text { Column 13: } & \text { CC1G03 Allele } 2 \\ \text { Column 14: } & \text { RAG1 Allele } 1 \\ \text { Column 15: } & \text { RAG1 Allele } 2 \\ \text { Column 16: } & \text { CMOS Allele } 1 \\ \text { Column 17: } & \text { CMOS Allele } 2 \\ \text { Column 18: } & \text { RAG2 Allele } 1 \\ \text { Column 19: } & \text { RAG2 Allele } 2 \\ \text { Column 20: } & \text { R35 Allele } 1 \\ \text { Column 21: } & \text { R35 Allele } 2 \\ \text { Column 22: } & \text { BDNF Allele } 1 \\ \text { Column 23: } & \text { BDNF Allele } 2\end{array}$

Dataset Item 2 (Table). The haplotypes (alleles) found. The column Haplotype refers to the haplotype identification code. The column Gene indicates the locus which the haplotype (allele) was found. A total of five codes are found in this column: BDNF, R35, RAG1, RAG2, and CMOS, which represent the name of the nuclear locus sequenced. The column Species refers to which species the haplotype is typical. The code Lo refers to L. olivacea, $\mathrm{Cm}$ refers to C. mydas, Ei refers to $E$. imbricata, Cc refers to C. caretta, Ei/Cc refers to a haplotype found in both E. imbricata and C. caretta, and Ei/Lo refers to a haplotype found in E. imbricata and L. olivacea. The last column, GenBank Accession Number, refers to the number of identification in the GenBank.

Column 1: Haplotype

Column 2: Gene

Column 3: Species

Column 4: GenBank Accession Number

Dataset Item 3 (Table). The GenBank accession numbers for each sample. No data is shown by a question mark. Each gene is represented by two columns, corresponding to the two alleles found.

$\begin{array}{ll}\text { Column 1: } & \text { Sample Code } \\ \text { Column 2: } & \text { RAG1 Allele 1 } \\ \text { Column 3: } & \text { RAG1 Allele 2 } \\ \text { Column 4: } & \text { CMOS Allele 1 } \\ \text { Column 5: } & \text { CMOS Allele 2 } \\ \text { Column 6: } & \text { RAG2 Allele 1 } \\ \text { Column 7: } & \text { RAG2 Allele } 2 \\ \text { Column 8: } & \text { R35 Allele 1 } \\ \text { Column 9: } & \text { R35 Allele 2 } \\ \text { Column 10: } & \text { BDNF Allele 1 } \\ \text { Column 11: } & \text { BDNF Allele 2 }\end{array}$

Dataset Item 4 (Nucleotide Sequences). Sequences with the BDNF exon alignment. The five aligned sequences are identified as haplotype number followed by the GenBank reference number.

Dataset Item 5 (Nucleotide Sequences). Sequences with the CMOS exon alignment. The eleven aligned sequences are identified as haplotype number followed by the GenBank reference number.

Dataset Item 6 (Nucleotide Sequences). Sequences with the R35 intron alignment. The thirteen aligned sequences are identified as haplotype number followed by the GenBank reference number.

Dataset Item 7 (Nucleotide Sequences). Sequences with the RAG1 exon alignment. The nine aligned sequences are 
identified as haplotype number followed by the GenBank reference number.

Dataset Item 8 (Nucleotide Sequences). Sequences with the RAG2 exon alignment. The six aligned sequences are identified as haplotype number followed by the GenBank reference number.

\section{Concluding Remarks}

The dataset presented here is the first populational study in sea turtles using nuclear sequences. Studies with sea turtles generally use mitochondrial markers to investigate hybridization or population structure. Mitochondrial markers are a great source of information for sea turtles, since they are philopatric species and, therefore, exhibit great structuration in mitochondrial markers. These markers are also useful to trace the origin of individuals in a given feeding area or where nesting turtles are migrating to feed, and many studies use Mixed Stock Analysis associated with mtDNA to uncover these migrations. In the specific case of Brazil, the use of only mtDNA can mask potential hybrid individuals, so the use of nuclear markers, especially sequences or SNPs, enables a better description of the population. With a crescent use of genome-wide studies and genomic methodologies, the next natural step is to investigate in depth the genome of these hybrid individuals and infer the evolutionary patterns of turtle genomes that made these high rates of natural hybridization in the Brazilian population possible.

\section{Dataset Availability}

The dataset associated with this Dataset Paper is dedicated to the public domain using the $\mathrm{CC} 0$ waiver and is available at http://dx.doi.org/10.1155/2013/196492. In addition, Dataset Items 1 and 2 associated with this Dataset Paper are available at doi:10.1111/j.1365-294X.2012.05685.x, and Dataset Items 38 are available under DRYAD entry doi:10.5061/dryad.j5240.

\section{Conflict of Interests}

There is no conflict of interests in the access or publication of this dataset.

\section{References}

[1] P. Lara-Ruiz, G. G. Lopez, F. R. Santos, and L. S. Soares, "Extensive hybridization in hawksbill turtles (Eretmochelys imbricata) nesting in Brazil revealed by mtDNA analyses," Conservation Genetics, vol. 7, no. 5, pp. 773-781, 2006.

[2] S. T. Vilaça, S. M. Vargas, P. Lara-Ruiz, É. Molfetti, E. C. Reis et al., "Nuclear markers reveal a complex introgression pattern among marine turtle species on the Brazilian coast," Molecular Ecology, vol. 21, no. 17, pp. 4300-4312, 2012.

[3] E. C. Reis, L. S. Soares, S. M. Vargas et al., "Genetic composition, population structure and phylogeography of the loggerhead sea turtle: colonization hypothesis for the Brazilian rookeries," Conservation Genetics, vol. 11, no. 4, pp. 1467-1477, 2010.
[4] E. Naro-Maciel, A. C. V. Bondioli, M. Martin et al., "The interplay of homing and dispersal in green turtles: a focus on the southwestern atlantic," Journal of Heredity, vol. 103, no. 6, pp. 792-805, 2012.

[5] S. M. Vargas, F. C. F. Araújo, D. S. Monteiro et al., "Genetic diversity and origin of leatherback turtles (Dermochelys coriacea) from the Brazilian coast," Journal of Heredity, vol. 99, no. 2, pp. 215-220, 2008.

[6] M. Â. Marcovaldi, G. G. Lopez, L. S. Soares, E. H. S. M. Lima, J. C. A. Thomé, and A. P. Almeida, "Satellite-tracking of female loggerhead turtles highlights fidelity behavior in northeastern Brazil," Endangered Species Research, vol. 12, no. 3, pp. 263-272, 2010.

[7] M. A. Marcovaldi, G. G. Lopez, L. S. Soares, and M. Lopez-Mendilaharsu, "Satellite tracking of hawksbill turtles Eretmochelys imbricata nesting in northern Bahia, Brazil: turtle movements and foraging destinations," Endangered Species Research, vol. 17, no. 2, pp. 123-132, 2012.

[8] A. C. C. D. Da Silva, E. A. P. Dos Santos, F. L. Das C. Oliveira et al., "Satellite-tracking reveals multiple foraging strategies and threats for olive ridley turtles in Brazil," Marine Ecology Progress Series, vol. 443, pp. 237-247, 2011.

[9] B. J. Godley, E. H. S. M. Lima, S. Åkesson et al., "Movement patterns of green turtles in Brazilian coastal waters described by satellite tracking and flipper tagging," Marine Ecology Progress Series, vol. 253, pp. 279-288, 2003.

[10] S. T. Vilaçaa, P. Lara-Ruiza, M. A. Marcovaldib, L. S. Soaresb, and F. R. Santos, "Population origin and historical demography in hawksbill (Eretmochelys imbricata) feeding and nesting aggregates from Brazil.," Journal of Experimental Marine Biology and Ecology, vol. 446, pp. 334-344, 2013.

[11] B. Ewing, L. Hillier, M. C. Wendl, and P. Green, "Basecalling of automated sequencer traces using phred. I. Accuracy assessment," Genome Research, vol. 8, no. 3, pp. 175-185, 1998.

[12] B. Ewing and P. Green, "Base-calling of automated sequencer traces using phred. II. Error probabilities," Genome Research, vol. 8, no. 3, pp. 186-194, 1998.

[13] D. Gordon, C. Abajian, and P. Green, "Consed: a graphical tool for sequence finishing," Genome Research, vol. 8, no. 3, pp. 195202, 1998.

[14] S. Kumar, M. Nei, J. Dudley, and K. Tamura, "MEGA: a biologist-centric software for evolutionary analysis of DNA and protein sequences," Briefings in Bioinformatics, vol. 9, no. 4, pp. 299-306, 2008.

[15] E. Naro-Maciel, M. Le, N. N. FitzSimmons, and G. Amato, "Evolutionary relationships of marine turtles: a molecular phylogeny based on nuclear and mitochondrial genes," Molecular Phylogenetics and Evolution, vol. 49, no. 2, pp. 659-662, 2008.

[16] D. A. Nickerson, V. O. Tobe, and S. L. Taylor, "PolyPhred: automating the detection and genotyping of single nucleotide substitutions using fluorescence-based resequencing," Nucleic Acids Research, vol. 25, no. 14, pp. 2745-2751, 1997.

[17] M. Stephens, J. S. Sloan, P. D. Robertson, P. Scheet, and D. A. Nickerson, "Automating sequence-based detection and genotyping of SNPs from diploid samples," Nature Genetics, vol. 38, no. 3, pp. 375-381, 2006.

[18] R. K. Aggarwal, T. P. Velavan, D. Udaykumar et al., "Development and characterization of novel microsatellite markers from the olive ridley sea turtle (Lepidochelys olivacea)," Molecular Ecology Notes, vol. 4, no. 1, pp. 77-79, 2004. 
[19] B. M. Shamblin, B. C. Faircloth, M. Dodd et al., "Tetranucleotide microsatellites from the loggerhead sea turtle (Caretta caretta)," Molecular Ecology Notes, vol. 7, no. 5, pp. 784-787, 2007.

[20] J. R. Wood, F. E. Wood, and K. Critchley, "Hybridization of Chelonia mydas and Eretmochelys imbricata," Copeia, vol. 3, pp. 839-842, 1983.

[21] S. A. Karl, B. W. Bowen, and J. C. Avise, "Hybridization among the ancient mariners: characterization of marine turtle hybrids with molecular genetic assays," Journal of Heredity, vol. 86, no. 4, pp. 262-268, 1995.

[22] J. A. Seminoff, S. A. Karl, T. Schwartz, and A. Resendiz, "Hybridization of the green turtle (Chelonia mydas) and hawksbill turtle (Eretmochelys imbricata) in the Pacific Ocean: indication of an absence of gender bias in the directionality of crosses," Bulletin of Marine Science, vol. 73, no. 3, pp. 643-652, 2003.

[23] K. Hirate and N. Kamezaki, "On the hybridization between the green turtle and the hawksbill turtle," Umigame Newsletter, vol. 20, p. 20, 1994.

[24] N. Kamezaki, Y. Nakajima, and M. Ishii, "Rapid communication: hybrids between Caretta caretta $\times$ Chelonia mydas from the Horinouchi Beach, Miyazaki," Umigame Newsletter, vol. 30, pp. 7-9, 1996.

[25] M. C. James, K. Martin, and P. H. Dutton, "Hybridization between a green turtle, Chelonia mydas, and loggerhead turtle, Caretta caretta, and the first record of a green turtle in Atlantic Canada," Canadian Field-Naturalist, vol. 118, no. 4, pp. 579-582, 2004.

[26] N. Kamezaki, "The possibility of hybridization between the loggerhead turtle, Caretta caretta, and the hawksbill turtle, Eretmochelys imbricata, in specimens hatched from eggs collected in Chita Peninsula," Japanese Journal of Herpetology, vol. 10, pp. 52-53, 1983.

[27] J. Frazier, "Sea turtles in the land of the dragon," Sanctuary Asia, vol. 8, pp. 15-23, 1988.

[28] M. B. Conceicao, J. A. Levy, L. F. Marins, and M. A. Marcovaldi, "Electrophoretic characterization of a hybrid between Eretmochelys imbricata and Caretta caretta (Cheloniidae)," Comparative Biochemistry and Physiology B, vol. 97, no. 2, pp. 275-278, 1990.

[29] A. L. Bass, D. A. Good, K. A. Bjorndal et al., “Testing models of female reproductive migratory behaviour and population structure in the Caribbean hawksbill turtle, Eretmochelys imbricata, with mtDNA sequences," Molecular Ecology, vol. 5, no. 3, pp. 321-328, 1996.

[30] R. J. Greenblatt, T. M. Work, P. Dutton et al., "Geographic variation in marine turtle fibropapillomatosis," Journal of Zoo and Wildlife Medicine, vol. 36, no. 3, pp. 527-530, 2005.

[31] N. Kamezaki and T. Namikawa, "Electrophoretic evidence for a case of natural hybridization between the loggerhead turtles, Caretta caretta, and the hawksbill turtle, Eretmochelys imbricata," Japanese Journal of Herpetology, vol. 10, no. 4, p. 108, 1984.

[32] R. C. Barber, C. T. Fontaine, J. P. Flanagan, and E. E. Louis Jr., "Natural hybridization between a Kemp's ridley (Lepidochelys kempii) and loggerhead sea turtle (Caretta caretta) confirmed by molecular analysis," Chelonian Conservation and Biology, vol. 4, no. 3, pp. 701-704, 2003. 

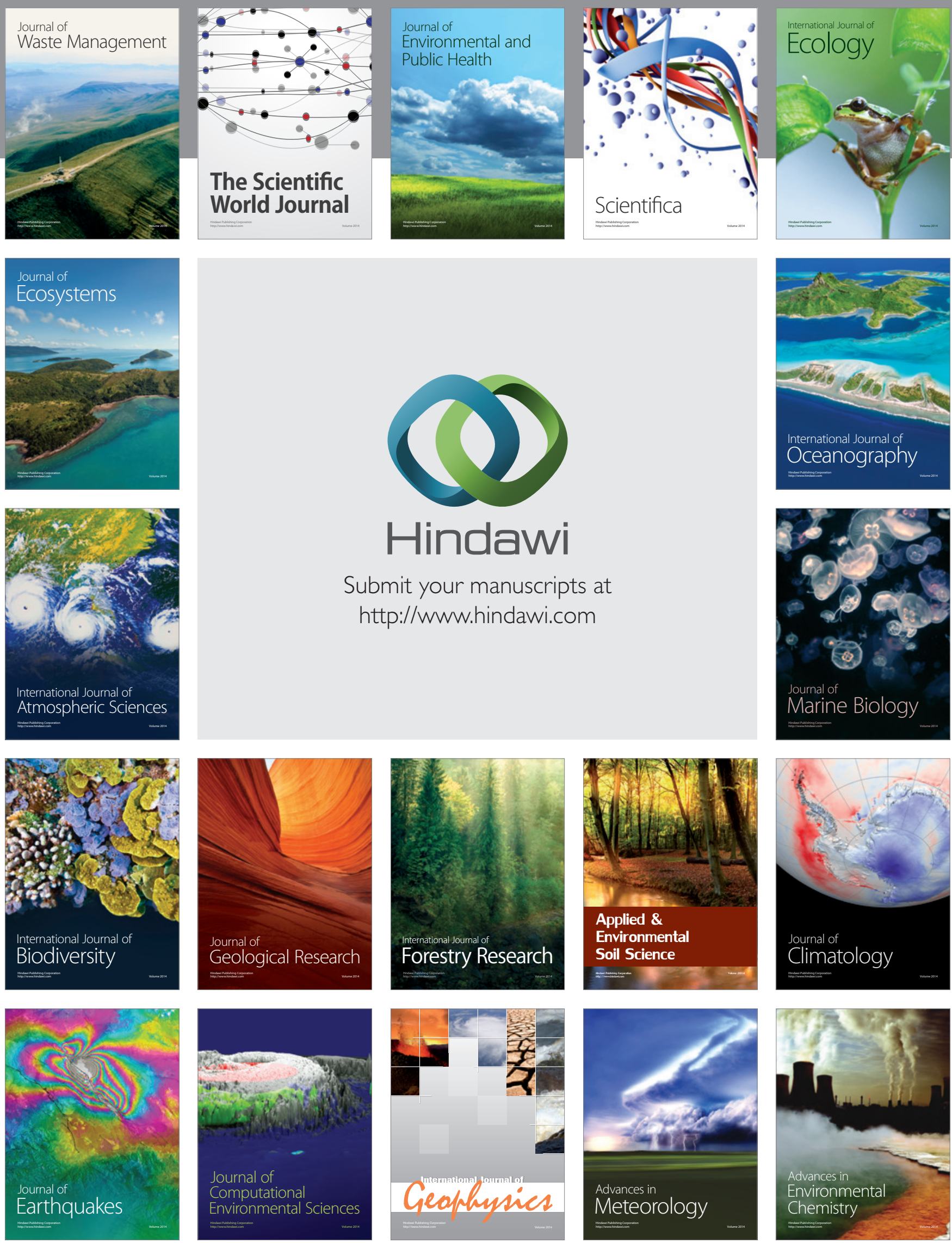